\title{
Influence of Dicalcium Silicate and Tricalcium Aluminate Compounds in Different Local Cement Brands on the Compressive Strength of Normal Concrete
}

\author{
A.N Ede ${ }^{1, a}$, O.M Olofinnade ${ }^{1, b^{*}}$, A.I. Akpabot ${ }^{1, c}$, S.O Oyebisi ${ }^{1, d}$, \\ and D.O Nduka ${ }^{2, \mathrm{e}}$
}

${ }^{1}$ Department of Civil Engineering, Covenant University, PMB 1023, Ota, Nigeria

2Department of Building Technology, Covenant University, PMB 1023, Ota, Nigeria

aanthony.ede@covenantuniversity.edu.ng, b rotimi.olofinnade@covenantuniversity.edu.ng, cakpabot.akpabot@covenantuniversity.edu.ng, dsolomon.oyebisi@covenantuniversity.edu.ng, edavid.nduka@covenantuniversity.edu.ng

Keywords: Compressive Strength, Bogue composition, Portland cement, Setting time, Workability, Normal strength concrete

\begin{abstract}
The mould-ability of concrete into intricate forms and the versatility of its constituent materials has made concrete to be the most preferred construction material. However, in developing nations such as Nigeria, poor quality of concrete is listed among the common causes of building collapse. Thus, this study investigated the effects of chemical compounds of four commonly used local ordinary Portland cement brands on the compressive strength of normal concrete. The cement was labelled brands A, B, C, and D, respectively, while all the other constituent materials remained constant in this study. The HACH DR 200 direct reading spectrophotometer method was used to analyze the composition of the oxide in each of the cement samples, while the Bogue composition formula was used to estimate the compound compositions of the cement samples. A designed mix proportion of 1:2:4 (cement: sand: granite) at water-cement ratio $(\mathrm{w} / \mathrm{c})$ of 0.6 was used to produce the concrete with an expected target strength of $25 \mathrm{~N} / \mathrm{mm}^{2}$. Also, the initial and final setting time of the cement samples and the workability of the concrete mixes were determined. Forty-Eight (48) numbers cube samples were cast and tested for compressive strength at 3, 7, 14, and 28 curing days, respectively, using a $150 \mathrm{~mm}$ concrete cubes. The result shows the setting time of the cement samples to be within an acceptable period. Also, results indicated that the cement brands have a significant percentage of Tricalcium Silicate $\left(\mathrm{C}_{3} \mathrm{~S}\right)$ content and low percentage Dicalcium Silicate $\left(\mathrm{C}_{2} \mathrm{~S}\right)$ content responsible for faster hydration rate and higher early strength gain of the concrete. However, it was observed that a higher percentage of Tricalcium aluminate $\left(\mathrm{C}_{3} \mathrm{~A}\right)$ leads to higher strength gain from 7 to 28 days of curing age.
\end{abstract}

\section{Introduction}

All over the world, many types of materials are used for infrastructure construction; however, concrete remains the most universally preferred materials for structural buildings than any other materials[1]. The excellent property of concrete in compressive strength, ability to be adapted to virtually any form, and excellent fire resistance coupled with the availability of constituent materials have all contributed to making it to be adopted massively worldwide [1 - 3]. In a study by Penttala [2], it was stated that concrete is one of the most malleable and continuously evolving building materials around the world. Studies within the last few years have shown that concrete can be transformed into a custom-made material consisting of several new constituents to meet the particular requirements of the construction industry [3-7]. The desire to meet the needs of the ever-increasing population of the world has led to an overstretching demand for essential infrastructural development and therefore, higher demands for concrete materials. Concrete is mostly useful in compressive, but weak in tension, for which it is regularly reinforced with tensile such as steel. Steel is manufactured under controlled environment and the properties easily certified, making it easier for adoption for safe construction [8]. Conversely, concrete properties vary considerably because of the influence of many 